\title{
Infection of juvenile salmon Salmo salar with a Dermocystidium-like organism in Sweden
}

\author{
Johan Höglund ${ }^{1}$, Anders Alfjorden ${ }^{2}$, Tapio Nikkilä ${ }^{3}$ \\ 'Department of Parasitology, National Veterinary Institule and Swedish University of Agricultural Sciences, Box 7073 , \\ S-750 07 Uppsala, Sweden \\ ${ }^{2}$ National Veterinary Institute, Department of Fish, Box 7073, S-750 07 Uppsala, Sweden \\ ${ }^{3}$ Swedish University of Agricultural Sciences, Faculty of Veterinary Medicine, Department of Pathology, \\ S-750 07 Uppsala, Sweden
}

\begin{abstract}
Free spores of a Dermocystidium-like organism were recovered from the epidermis and covering mucus of gills and fins of moribund farmed salmon Salmo salar. The parasite appeared in juvenile fish only and at low water temperatures $\left(\leq 5^{\circ} \mathrm{C}\right)$. The most prominent external macroscopical clinical signs of disease were thickened fins that gave the tips a pronounced greyish opaque appearance often in combination with signs of fin rot/fin erosion. The gills were swollen and pale and could also be necrotic. Examination of fresh mounts and tissues prepared for light and electron microscopy showed vacuolated spherical spores typical for parasites of the genus Dermocystidium. Irregularly vacuolated spores with 1 or multiple nuclei were also observed. Histological examination of infected salmon indicated concurrent Flexibacter sp. infection that was verified in Gram-negative stained imprints. The present finding is the first observation of Dermocystidium in Sweden. In addition, this is the first record of a Dermocystidium-like agent that occurs freely in the mucus and epidermis of freshwater teleosts.
\end{abstract}

KEY WORDS: Salmon $\cdot$ Salmo salar $\cdot$ Parasite $\cdot$ Protozoa $\cdot$ Histology

\section{INTRODUCTION}

The genus Dermocystidium is comprised of unicellular parasites of an uncertain taxonomic position. Controversy still exists whether these minute spherical organisms should be assigned to the Protozoa or to lower fungi (Lom \& Dykova 1992). The genus was already described at the beginning of this century, but data on the early development and modes of transmission are still fragmentary for many of the species. Nevertheless, a nucleated spore with a large central vacuole or refractile body, i.e. a signet ring cell or hypnospore, is a developmental stage most Dermocystidium species have in common (Lom \& Dykova 1992). Dermocystidium species are often parasitic of young or juvenile fish and infection usually commences when water conditions are cold. Disease outbreaks have been associated with fish mortalities

•E-mail: johan.hoglund@sva.se
(Pauley 1967, Allen et al. 1968, McVicar \& Wootten 1980, Hedrick et al. 1989, Nash et al. 1989).

The genus is known from a wide variety of freshwater teleosts but also from certain amphibians in Europe, Asia and North America (Reichenbach-Klinke 1965, 1980, Bauer 1984, Lom \& Dykova 1992). The vegetative spores of many species are often found enclosed within macroscopically visible cutaneous cysts with a distribution more or less restricted to certain sites of the fish host. Dermocystidium branchiale Léger, 1914, and D. salmonis Davis, 1947, are the only cyst-forming species known from salmonid fish. D. branchiale has been reported from the gills of Salmo trutta $m$. fario in Europe, whereas $D$. salmonis occurs in the gills, skin and spleen of Oncorhynchus tschawytscha, O. gorbuscha and Coregonus lavaretus in Northern America.

In contrast, certain Dermocystidium-like organisms are only known as chronic internal systemic infections. They are all restricted to salmonid fish of the genera Salmo and Oncorhynchus both in Europe and North 

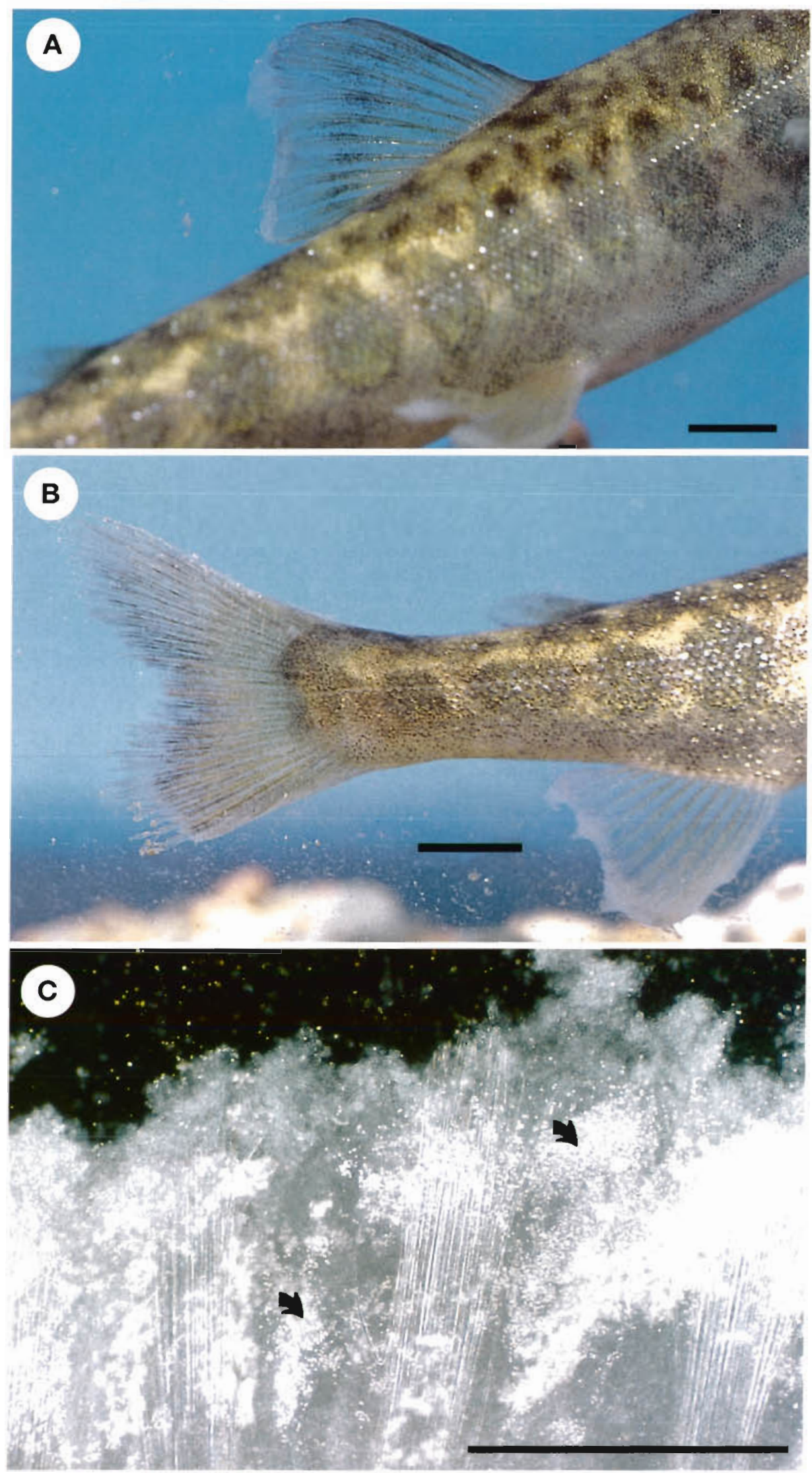

Fig. 1. Salmo salar. Gross pathological signs caused by the Dermocystidium-like organism in (A) the dorsal fin of juvenile salmon, note the thickened tip of the fin; (B) the caudal fin of salmon concurrently infected with Flexibacter sp. showing signs of progressive erosion and disintegration of the soft tissues between the rays; (C) the distal tip of the pectoral fin (close up). Arrows: clusters of spores. Bars in $A$ and $B=1 \mathrm{~cm}$, in $C=1 \mathrm{~mm}$ 
America and have in general only been described at the generic level (McVicar \& Wootten 1980, van de Moer et al. 1988, Hedrick et al. 1989, Nash et al. 1989). For example, it has been suggested that the European visceral form of Dermocystidium sp. in S. salar of McVicar \& Wootten (1980) and the systemic Dermocystidium sp. in S. salar, S. trutta and O. mykiss by Nash et al. (1989) were identical (Lom \& Dykova 1992). On the other hand, D. macrophagi van de Moer, Manier \& Bouix, 1987, was found inside the blood cells of $O$. mykiss in Europe and is considered to be a distinct species.

In this paper we report on a Dermocystidium-like agent recovered while performing routine health monitoring of juvenile salmon Salmo salar in Sweden. The spore morphology of the parasite and the pathological damage inflicted to the host is described in detail.

\section{MATERIAL AND METHODS}

Fish. The fish included in this study were obtained in a routine health monitoring programme of farmed juvenile salmon Salmo salar at the National Veterinary Institute in Sweden. Fish that arrived at the Institute in February, April, November and December 1995 were dissected and affected tissues were sampled.

Light microscopy. The spore morphology was examined in unstained fresh-and/or formalin fixed wet mounts but also in air-dried imprints stained with Giemsa's solution in a Olympus BH-2 light microscope. Imprints were also Gram-stained and subsequently examined for Flexibacter sp. Samples for histological examination were fixed in $4 \%$ buffered formaldehyde and embedded in paraffin-wax blocks. Histological sections were made and stained with H\&E solution or using the periodic acid-Schiff reaction (PAS) and then examined by light microscopy.

Electron microscopy. Samples for transmission electron microscopy were fixed in a phosphate buffered (pH 7.2) mixture containing $1.5 \%$ glutaraldehyde and $1.5 \%$ paraformaldehyde, postfixed in $1 \% \mathrm{OsO}_{4}$ for $1 \mathrm{~h}$, dehydrated in graded series of ethanol and embedded in Agar-100-resin. Semithin sections were stained with toluidine blue, and ultrathin sections were contrasted with uranyl acetate and lead citrate before examination in a Philips 420 transmission electron microscope.

\section{RESULTS}

\section{Clinical and gross pathology}

Infected salmon were emaciated and lethargic, and fish with severely damaged gills exhibited signs of respiratory distress. The fins were slightly thickened and often had a pronounced greyish opaque appearance of the skin surface (Fig. 1A). In more adversely affected fish there were signs of progressive erosion and disintegration of the soft tissues between the fin rays (Fig. 1B). These fish were often simultaneously infected with Flexibacter sp. All fins except the adipose fin were found to be affected. The spores were distributed freely in the soft tissues and cysts or capsules with Dermocystidium were never observed (Fig. 1C). The most distinctive clinical sign of the gill region was an excessive mucus and epithelial production giving the gills a swollen and somewhat pale appearance.

\section{Microscopy}

Wet fresh mount preparations of the gills and fins of infected salmon revealed a massive numbers of spherical to oval spores that were about 7 to $12 \mu \mathrm{m}$ in diameter. Several morphological distinctive kinds of spores probably representing different developmental stages of the parasite were observed. The most characteristic type, i.e. the signet ring cell or hypnospore, had a large refringent vacuole with a narrow rim of cytoplasm (Fig. 2A), whereas other spores were irregularly vacuolated and equipped with one or multiple more prominent nuclei (Fig. 2B). The spores were readily detected in Giemsa-stained imprints; however, as most spores appeared as dark-stained spherical bodies, it was impossible to differentiate between different stages of development. In histological sections the spores appeared to be slightly PAS-positive and they were clearly visible in the epidermis and covering mucus of gills and fins (Fig. 2C). The spores were found both superficially in the mucus layer and deeper down in the epidermis (Fig. 2D). The epithelium of both the gills and fins was sometimes displaced, degenerated or necrotic probably due to concurrent Flexibactersp. infection. The inflammatory tissue reaction mounted by the host was minimal.

\section{Electron microscopy}

Ultrastructurally, the spores of the Dermocystidium sp. in salmon were oval or spherical. Primarily the spores contained a large vacuole and a nucleus with a well-defined nucleolus (Fig. 3A). In the cytoplasm there was a Golgi complex and an endoplasmatic reticulum. Numerous structures suggestive of mitochondria and small vesicles containing fine electrondense granules were also observed. The spores were surrounded by an irregular multilaminated membrane. In some spores outgrowths of filamentous projections were observed. These cells also had a prominent 


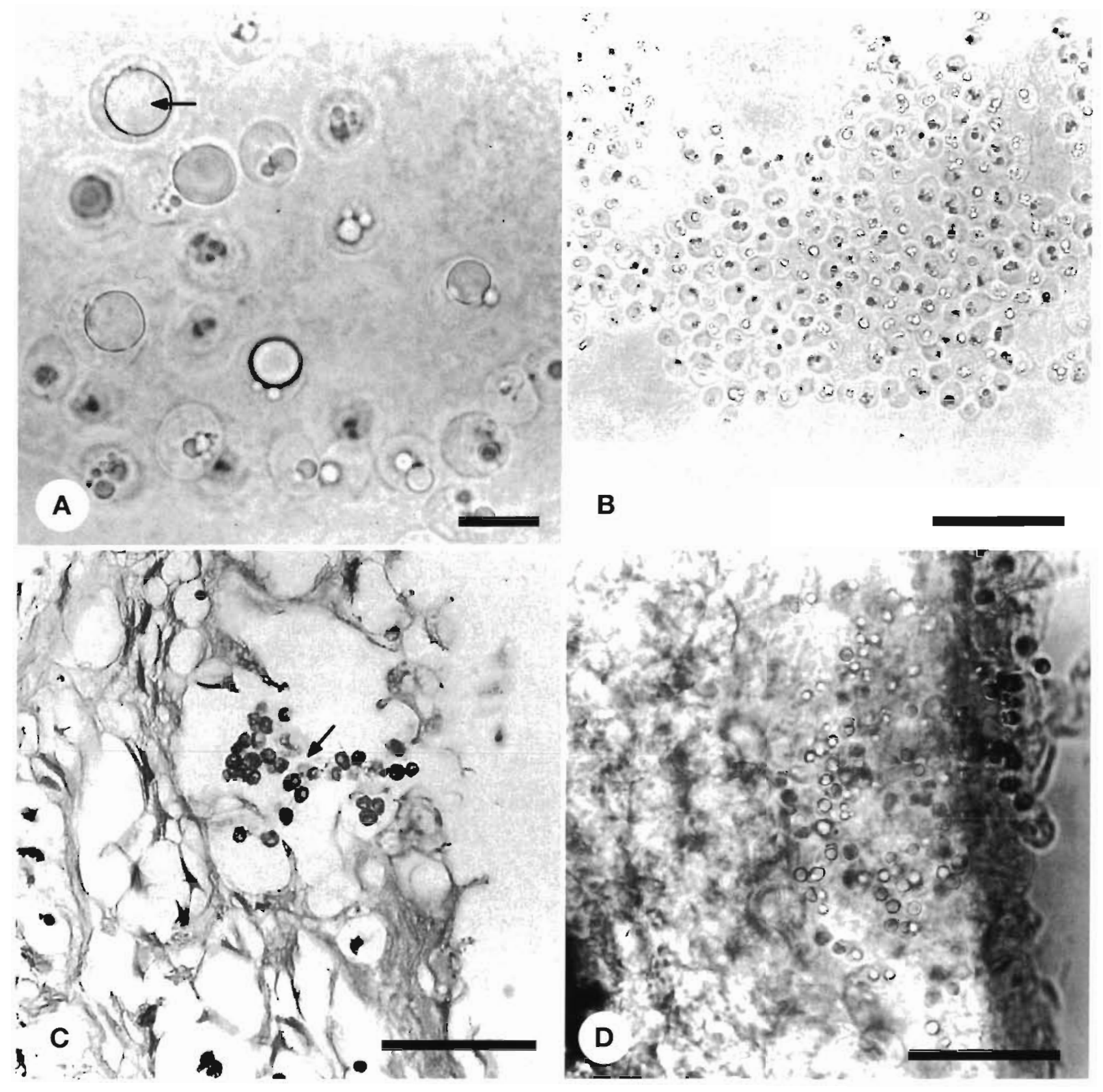

Fig. 2. $(A, B)$ Wet mounts of the Dermocystidium-like organism in the epidermis and covering mucus of the fins in salmon. Arrow: signet ring cell. (C) Histological appearance of the parasite in the epidermis of salmon; (D) wet mount of the same piece as sectioned in C. Arrow: spores. Bars in A, B $=10 \mu \mathrm{m}$, in C, D = 50 $\mu \mathrm{m}$

nucleus with a nucleolus and there seemed to be an increase in both the number and size of mitochondria whereas the vacuoles were smaller (Fig. 3B).

\section{DISCUSSION}

In the present study we describe the spore morphology, histological appearance and gross pathological signs of a Dermocystidium-like agent in the gills and fins of farmed juvenile salmon Salmo salar. This is the first description of a Dermocystidium-like organism with free spores in the epidermis and covering mucus of a freshwater teleost. It is also the first report on Dermocystidium-like infection in Sweden.

Although this paper does not shed light on the taxonomic affinities of the genus Dermocystidium, a comparison between existing species and that described in the present study was made. The typical nucleated signet ring cell or hypnospore characterised by a large 
Fig. 3. Transmission electron micrograph of Dermocystidium-like species from the epidermis and covering mucus of a naturally infected salmon: (A) Signet ring cell or hypnospore; (B) spore with filamentous projections (arrow). Magnification in A and $\mathrm{B}=\times 2500$ $\mathrm{V}$ : vacuole, $\mathrm{N}$ : nucleus, $\mathrm{M}$ : mitochondria, G: Golgi-complex

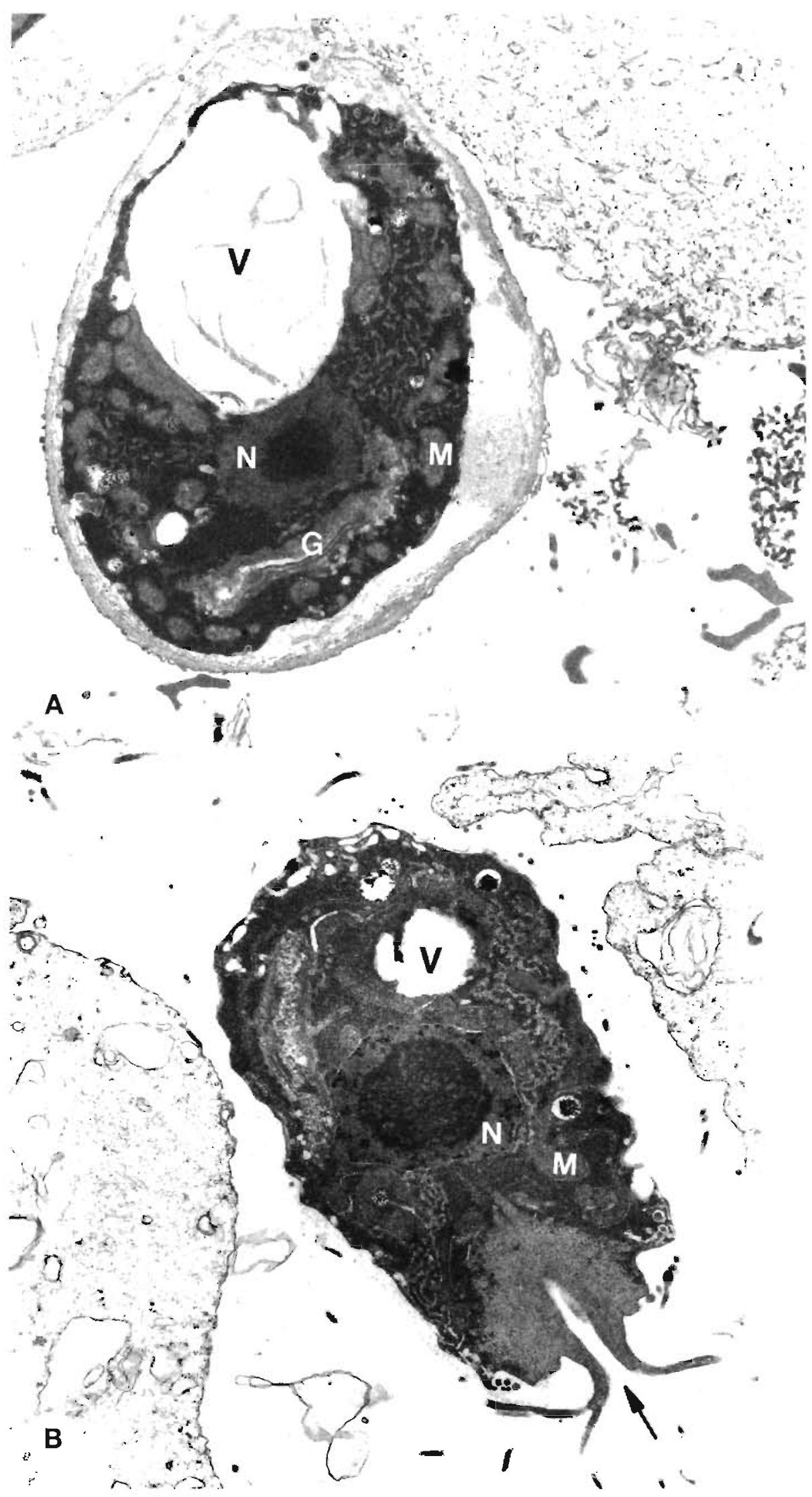


central vacuole was a feature the present organism had in common with many of the previously described members of the genus. Ultrastructural characteristics of the hypnospores were a prominent vacuole surrounded by a dense cytoplasm with numerous mitochondria, vesicles with electron-dense granules, Golgicomplex, endoplasmatic reticulum and a nucleus with a well-defined nucleosome. Thus, in some respects the present organism resembled the systemic Dermocystidium in the internal organs of salmonids that was described by Nash et al. (1989), but also to some extend the visceral agent of salmon described by McVicar \& Wootten (1980). Furthermore, it was PASpositive like the systemic Dermocystidium infections of salmonids described by Hedrick et al. (1989) and Nash et al. (1989). However, in the Dermocystidium described by Hedrick et al. (1989), a prominent vacuole was not found. The parasite observed in salmon in our study also had similarities to $D$. salmonis in the choice of host species and predilection site. However, unlike $D$. salmonis it was never found enclosed within cysts (Davis 1947), and the ultrastructural characteristics were also different (Olson et al. 1991).

In addition to signet ring cells or hypnospores, multinucleated dividing cells that probably reflected different developmental stages were observed. Electron microscopy also revealed spores with a less prominent vacuole that seemed to be motile. It has been suggested that the signet ring cell represent a vegetative stage that may sporulate to produce infective zoospores (Wotten \& McVicar 1980), and it was experimentally demonstrated that uniflagellated zoospores developed from spores within gill cysts from Dermocystidium salmonis (Olson et al. 1991). Despite some similarities in spore size and morphology, the striking difference in the choice of microhabitat between the present parasite of salmon and those described earlier from salmonids suggests that this is a previously unknown species.

A most interesting finding in the present study was the concurrent Dermocystidium and Flexibacter sp. infections. It was evident from the histological observations that the epidermis and covering mucus of Dermocystidium infected fins could be more or less destroyed. Consequently, it seems likely that infected salmon were predisposed to secondary bacterial infection. A similar observation was made regarding an epizootic of Dermocystidium in the gills of sockeye salmon in British Columbia (Canada) in which it was suggested that affected fish were subjected to secondary bacterial gill disease (Wood 1974). It has also been found by other investigators that Dermocystidium infections were associated with outbreaks of PKD (van de Moer et al. 1988, Nash et al. 1989). However, a causal relationship between primary and secondary infection cannot be determined for the infectious agents observed in this study and definitive conclusions cannot be drawn until further experimental evidence is available

In conclusion, a Dermocystidium-like organism of juvenile salmon was described. It occurred freely in the epidermis and covering mucus of gills and fins of salmon. The organism seems to be of biological and economic significance as it was associated with lowlevel mortalities of juvenile salmon. Consequently, it is apparent that the present Dermocystidium of salmon should receive further attention in order to gain further insight into more aspects regarding its epidemiology. Without more knowledge about the life history and mode of transmission is it impossible to develop effective control measures.

Acknowledgements. We are indebted to Dr A. McVicar for comments on the manuscript.

\section{LITERATURE CITED}

Allen RL, Meekin TK, Pauley GB, Fujihara MP (1968) Mortality among Chinook salmon associated with the fungus Dermocystidium. J Fish Res Bd Can 25:2467-2475

Bauer ON (1984) Dermocystidium infections of cultured fish. Symp Biol Hung 23:181-185

Davis HS (1947) Studies of the protozoan parasites of freshwater fishes. U.S. Dept Interior Fish Bull, Washington 51: $1-29$

Hedrick RP, Friedman CS, Modin J (1989) Systemic infection in Atlantic salmon Salmo salar with a Dermocystidiumlike species. Dis Aquat Org 7:171-177

Lom J, Dykova I (1992) Developments in aquaculture and fisheries. Protozoan parasites of fishes, Vol 26. Elsevier Science Publishers, Amsterdam

McVicar A, Wootten R (1980) Diseases in farmed juvenile Atlantic salmon caused by Dermocystidium sp. In: Ahne W (ed) Fish diseases. Springer Verlag, Berlin, p 165-173

Nash G. Southgate P, Richards RH, Sochon E (1989) A systemic protozoal disease of cultured salmonids. J Fish Dis 12:157-173

Olson RE, Dungan CF, Holt RA (1991) Water-borne transmission of Dermocystidium salmonis in the laboratory. Dis Aquat Org 12:41-48

Pauley GB (1967) Prespawning adult salmon mortality associated with a fungus of the genus Dermocystidium. J Fish Res Bd Can 24:843-848

Reichenbach-Klinke HH (1965) The principal diseases of lower vertebrates. Academic Press, London

Reichenbach-Klinke HH (1980) Krankheiten und Schädigungen der Fische. Gustav Fischer Verlag, Stuttgart

van de Moer A, Manier JF, Bouix G (1988) Ultrastructural study of Dermocystidium macrophagi n. sp., an intracellular parasite of Salmo gairdneri. Ann Sci Nat Zool (Paris) 8:143-151 (in French)

Wood JW (1974) Diseases of Pacific salmon; their prevention and treatment. Washington State Dept Fish, Olympia, WA 